LEWTs, S. (1992) Sex and schizophrenia: vive la difference. British Jownal of Psychiatry, 161, 445-450.

JOHN M. EAgLeS

Ross Clinic

Royal Cornhill Hospital

Cornhill Road

Aberdeen AB9 2ZF

AUTHORs' RePLy: Dr Eagles raises two very interesting questions. In our paper we hypothesise that the decreasing first admission rates of schizophrenia in Denmark could be explained partly by a parallel decrease in available psychiatric beds. The reduction in capacity was about $50 \%$ during the study period. Dr Eagles suggests that the bed reduction "has been largely of long-stay beds, that is, not the type of beds which would be occupied by first admission schizophrenic patients", and therefore could not be responsible for the decrease in schizophrenia first admission rates.

Unfortunately, the Danish registration system does not distinguish between beds for acute admissions and beds for long-stay treatment. But the fact that we, in the period 1980-1989, found a reduction in long-stay patients admitted for more than five years from 1820 to 320 , a decrease of 1500 patients (census figures), might illustrate the situation. In the same period bed numbers were reduced by 2630 .

Of course, we should not reject the possibility of a genuine decrease in schizophrenia rates in the population. However, as we discuss in our paper, there are still some possible nosocomial explanations to be tested.

Dr Eagles also points to the gender disparity in our material: 5314 newly diagnosed male schizophrenics compared with only 3254 females. He underlines the hypothesis that narrowly defined schizophrenia may be less common among females than among males which "could constitute an important clue in the search for the causes of the disorder". We fully agree with that. The Institute of Psychiatric Demography, Aarhus, Denmark is a World Health Organisation (WHO) Collaborating Centre and over the past few years has been investigating this in conjunction with the WHOCollaborating Centre, Mannheim, Germany.

POVL MUNK-JøRGENSEN

Psychiatric Hospital Preben Bo Mortensen

Skovagervej 2

DK-8240 Riskov

Denmark

\section{Origins of Delusions}

SIR: I read with interest Dr Roberts' review article on the origins of delusions (Journal, September 1992,
161, 298-308). However, in an otherwise comprehensive review, in the section on psychodynamics, there is an omission of more recent psychoanalytic views on delusions. There is no mention of the concept of pathological projective identification, as formulated by Bion.

Based on detailed analytic work with schizophrenics, Bion described the genesis of hallucinations and their link with the formation of delusions. He differentiated the abnormal thinking process in the so-called psychotic part of the personality from the working of the non-psychotic personality. His views are not just of theoretical interest, but are, as I have attempted to illustrate elsewhere with clinical examples, of central importance in understanding psychotic patients' communications in general psychiatric practice (Lucas, 1991).

Dr Roberts comments that psychodynamic formulations on delusions are now giving way to cognitive psychology models. I believe the situation should not be regarded as a competitive one, but that each approach needs to be fully explored and appreciated in its own right. Bion has left us a rich legacy to explore further within general psychiatric practice.

Bron, W. R. (1967) Second Thoughts. New York: Jason Aronson. LuCAs, R. (1991) The psychotic personality. A psychoanalytic theory and its application in clinical practice. Psychoanalytic Psychotherapy, 6, 73-79.

\section{Claybury Hospital \\ Woodford Bridge \\ Woodford Green \\ Essex IG8 8BY}

Richard Lucas

AUTHOR's REPLY: I am grateful to Dr Lucas for drawing attention to the contribution of Bion. Since submitting the paper I have also been reminded of Jung's many ideas about the psychogenesis of delusions and the meaning of symptoms. My concern in constructing the review was to bring order into chaos and establish some means of navigating through a vast polyglot literature. In doing so I encountered what Roy Porter has called the "delicious danger of not knowing when to stop", and would welcome further correspondence with those able to point to any other significant omissions.

Dr Lucas also helpfully underlines the need for clinical work to be informed by wisdom wherever it may be found and the continuing value of psychodynamic insights to the daily practice of general psychiatry.

Holloway (1988) has emphasised that the care and treatment of patients suffering from long-term mental illness is ideally based on an "individualised 